\title{
Dietary antioxidants and periodontal disease in community- based older Japanese: a 2-year follow-up study
}

\author{
Masanori Iwasaki ${ }^{1, *}$, Paula Moynihan ${ }^{2}$, Michael C Manz ${ }^{3}$, George W Taylor ${ }^{4}$, \\ Akihiro Yoshihara $^{5}$, Kanako Muramatsu ${ }^{6}$, Reiko Watanabe ${ }^{6}$ and Hideo Miyazaki ${ }^{1}$ \\ ${ }^{1}$ Division of Preventive Dentistry, Department of Oral Health Science, Niigata University Graduate School of \\ Medical and Dental Sciences, 2-5274 Gakkocho-Dori, Chuo-Ku, Niigata 951-8514, Japan: ${ }^{2}$ Institute for Ageing \\ and Health/Centre for Oral Health Research, Newcastle University, Newcastle upon Tyne, UK: ${ }^{3}$ Department of \\ Cariology, Restorative Sciences, and Endodontics, School of Dentistry, University of Michigan, Ann Arbor, MI, \\ USA: ${ }^{4}$ Department of Preventive and Restorative Dental Sciences, University of California San Francisco, \\ San Francisco, CA, USA: ${ }^{5}$ Division of Oral Science for Health Promotion, Department of Oral Health and \\ Welfare, Niigata University Graduate School of Medical and Dental Sciences, Niigata, Japan: ${ }^{6}$ Department \\ of Health and Nutrition, Faculty of Human Life Studies, University of Niigata Prefecture, Niigata, Japan
}

Submitted 16 November 2011: Final revision received 23 March 2012: Accepted 30 March 2012: First published online 22 May 2012

\begin{abstract}
Objective: To investigate the longitudinal relationship between the intake of dietary antioxidants and periodontal disease in community-dwelling older Japanese.

Design: A retrospective cohort study, with a follow-up of 2 years (2003-2005). Intakes of dietary antioxidants (vitamin $\mathrm{C}$, vitamin $\mathrm{E}, \alpha$-carotene and $\beta$-carotene) were assessed with a validated FFQ. Participants were classified by tertile of antioxidant intake. Full-mouth periodontal status, measured as the clinical attachment level, was recorded at baseline and follow-up examinations. Periodontal disease progression was considered as loss of attachment of $3 \mathrm{~mm}$ or greater over the study period at the interproximal site for each tooth. Finally, the number of teeth with periodontal disease progression per person was calculated and was used as the outcome. Poisson regression analysis was conducted, with dietary antioxidants as the main exposure, to estimate their influence on the number of teeth with periodontal disease progression.

Setting: Niigata City (Japan).

Subjects: Dentate individuals aged 75 years in 2003, for whom data were available, were included in the analyses ( $n$ 264).

Results: A higher intake of dietary antioxidants was inversely associated with the number of teeth with periodontal disease progression, controlling for other variables. The multivariate-adjusted incidence rate ratios in the first, second and third tertiles were $1 \cdot 00,0.76(95 \%$ CI $0 \cdot 60,0 \cdot 97)$ and $0.72(95 \%$ CI $0.56,0 \cdot 93)$ for vitamin C; $1.00,0.79$ (95\% CI $0.62,0.99)$ and 0.55 (95\% CI $0.42,0.72)$, for vitamin E; and $1.00,1.02(95 \%$ CI $0.81,1 \cdot 29)$ and $0.73(95 \%$ CI $0.56,0.95)$ for $\beta$-carotene.

Conclusions: The study results suggest that higher intake of antioxidants may mitigate periodontal disease in community-dwelling older Japanese.
\end{abstract}

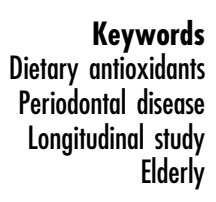

Periodontal disease is defined as an inflammatory condition of the periodontal tissues. Periodontal pocketing can occur with inflammation and swelling of the gingiva and/or destruction of the connective tissue and bone that support the teeth (Fig. 1). Advanced disease with deep periodontal pockets affects 10 to $15 \%$ of the world's population $^{(1)}$ and is a major cause of tooth loss in adults $^{(2)}$. The main aetiological agent in the causation of periodontal disease is dental plaque. According to previous reports, there are several risk factors for periodontal disease: hypoalbuminaemia ${ }^{(3)}$, hyperglycaemia (diabetes) ${ }^{(4)}$ and smoking ${ }^{(5)}$. Periodontal disease is characterized by hyper-inflammation, involving excess release of reactive oxygen species (ROS) by host neutrophils ${ }^{(6)}$. Increased ROS production causes oxidative stress $^{(7)}$ and contributes to tissue destruction by damaging DNA and proteins, causing lipid peroxidation and oxidation of other enzymes (e.g. antiproteases), and stimulating pro-inflammatory mediators through activation of the transcription factors NF- $\mathrm{KB}$ and activator protein $1^{(6,8,9)}$. Studies have demonstrated the 


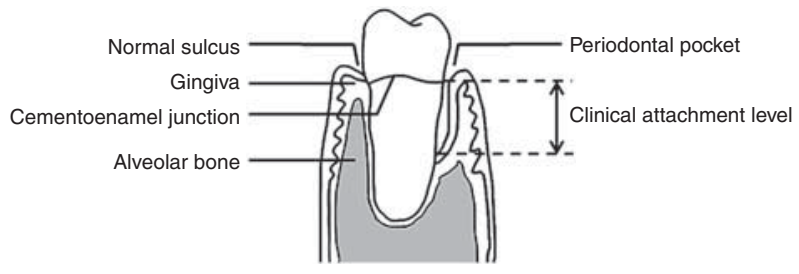

Fig. 1 Periodontal tissues

in vitro ability of ROS to degrade extracellular matrix components of the periodontal connective tissues (e.g. proteoglycans) ${ }^{(10)}$. Moreover previous study results indicate that ROS act as an intracellular signal mediator for osteoclast activation and differentiation ${ }^{(11)}$. These findings suggest that oxidative stress plays a significant role in the pathogenesis of periodontal disease. Oxidative stress is also associated with a higher risk of several chronic inflammatory diseases which relate to periodontal disease, such as diabetes ${ }^{(12)}$, rheumatoid arthritis ${ }^{(13)}$ and $\mathrm{CHD}^{(14)}$.

Dietary antioxidants, such as vitamin C, vitamin E and carotenoids, have been shown to be protective in a number of diseases involving chronic inflammation ${ }^{(15-19)}$. The mechanisms via which antioxidants protect biological systems from oxidative damage include the direct scavenging of ROS and the sequestration of free catalytic metal ions, which promote ROS formation ${ }^{(10)}$. There is some evidence of a negative association between antioxidant status and periodontal disease. For example, the association between low vitamin $\mathrm{C}$ intake and periodontal disease among smokers has been demonstrated in a cross-sectional study ${ }^{(20)}$. However, there are few data on the relationship between other antioxidant nutrients (e.g. vitamin E and carotenoids) and periodontal disease. Studies have demonstrated that both local and systemic antioxidant capacities were compromised in patients with periodontal disease ${ }^{(21-23)}$. It is unclear from these cross-sectional analyses whether this reflects a response to the neutrophil hyper-reactivity or is the result of reduced intake of dietary antioxidants, malabsorption or metabolic compromise because of polymorphisms in key redox-regulating enzymes ${ }^{(6,24,25)}$. To date, there are no data on the relationship of dietary antioxidants to changes in the periodontal condition over time.

Investigating the relationship between dietary antioxidants and the development of periodontal disease in a longitudinal study will help further elucidate the potential role of dietary modification in the prevention and treatment of periodontal disease and the ultimate prevention of tooth loss. The hypothesis of the present study was that a high intake of dietary antioxidant vitamins is associated with a lower risk of periodontal disease progression. The study aimed to determine if there was a longitudinal relationship between intake of dietary antioxidants and periodontal disease in community-dwelling older Japanese.
A further aim was to determine if the intakes of vegetables and fruits, primary food sources of dietary antioxidants, were associated with periodontal disease progression in this group of older people.

\section{Materials and methods}

\section{Study design and selection of study participants}

The current investigation was a subset study of the Niigata Study over the period 2003 to 2005. Briefly, the Niigata Study is a prospective community-based study initiated in 1998 to evaluate relationships between systemic health status and history of dental diseases. In April 1998, all 4542 Niigata citizens aged 70 years (2099 men and 2443 women) were sent a written request to participate in the survey. The invitation was mailed again to non-respondents 3 weeks later and, consequently, 81.4\% ( $n$ 3695) responded positively to participate in the survey. Considering the availability of resources, examination appointments could be arranged for 600 individuals. The final study sample was randomly recruited from several areas of Niigata in order to have an approximately equal number of men ( $n$ 306) and women $(n \text { 294) })^{(3)}$.

During 1998-2003, 230 of the 600 original participants were not available for the current study due to the following reasons: (i) 149 refused, (ii) forty-five were hospitalized, (iii) twenty-seven had died and (iv) nine had moved out of Niigata City; therefore, 370 individuals underwent dietary intake assessments, dental and medical examinations, interview and anthropometric evaluation in 2003 as part of the baseline assessment for the current study. At baseline, people who were already edentulous (i.e. having no teeth; $n$ 32) or who did not submit complete data ( $n$ 4) were excluded, leaving 334 eligible individuals to enter the study. Two years later, participants underwent follow-up examinations including dental assessment at which sixty-nine were not available to participate (sixty-four refused, four had died and one had moved out of Niigata City) and one became edentulous. Data were therefore analysed for the 264 dentate participants (141 men, 123 women) completing the follow-up examination in 2005. Figure 2 presents the flow diagram of study participation. The study was conducted according to the guidelines laid down in the Declaration of Helsinki and all procedures involving human subjects were approved by the Ethics Committee of the Faculty of Dentistry, Niigata University. Written informed consent was obtained from all study participants.

\section{Dietary intake assessment}

Dietary habits during the preceding month were assessed with a brief-type self-administered diet history questionnaire $(\mathrm{BDHQ})^{(26)}$. Responses to the BDHQ were checked for completeness and, where necessary, clarified by direct questioning of the participant. 
1998 Niigata study initiated

Niigata citizens, 70 years old, were sent a written request to participate in the survey ( $n$ 4542)

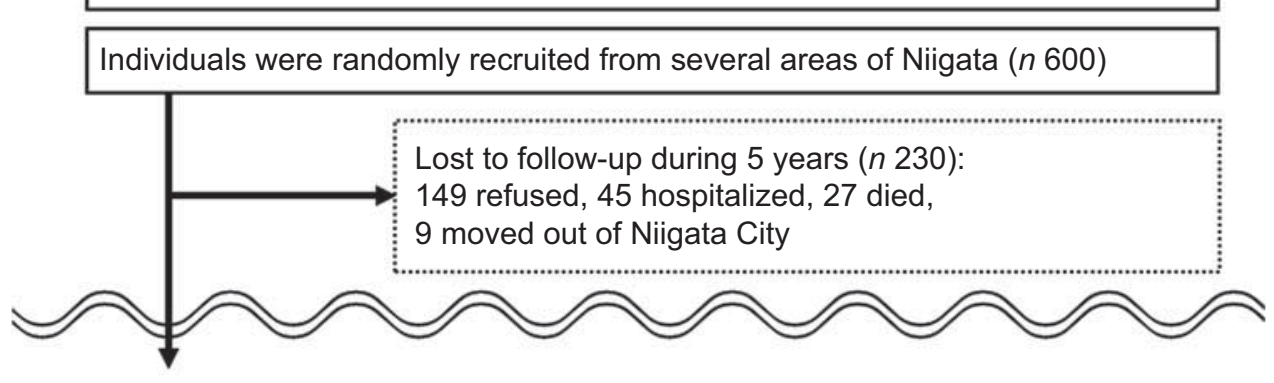

2003 Baseline survey for the current study

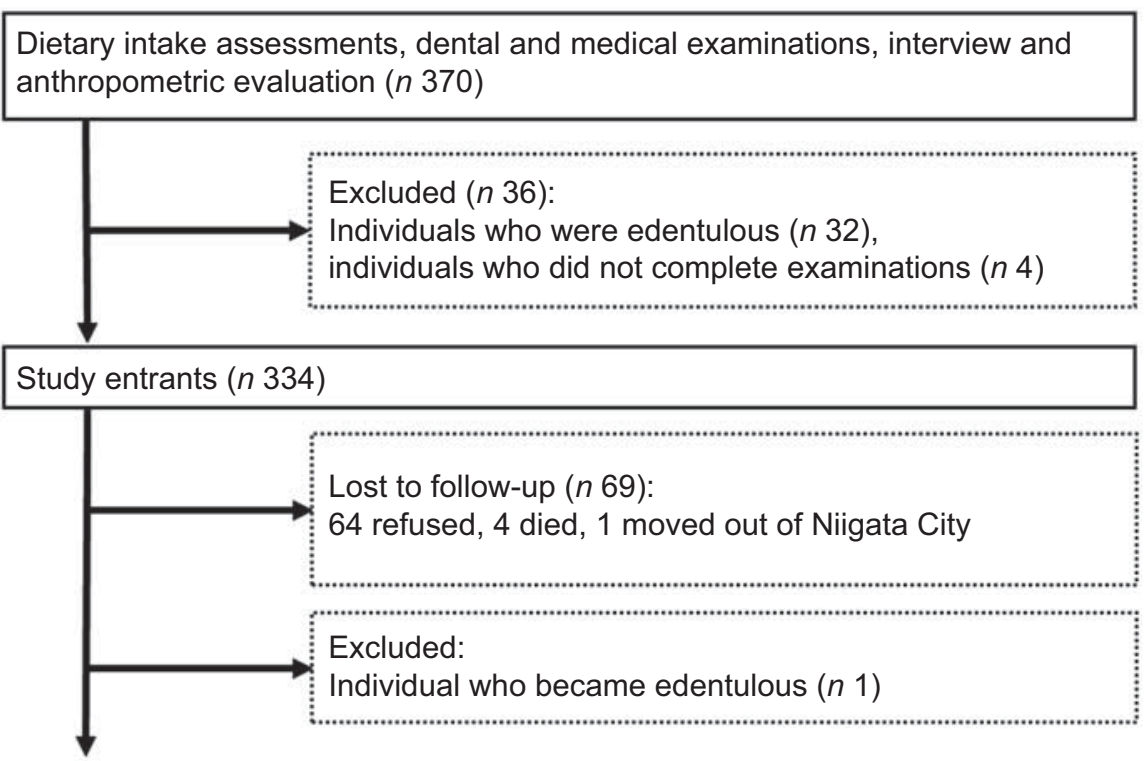

2005 Follow-up survey for the current study

Study participants underwent dental examination ( $n$ 264)

Participants/entrants $=79.0 \%$

Fig. 2 Flow diagram of participation in the study

The BDHQ is a validated questionnaire that enquires about the frequency of consumption of a total of fifty-six food and beverage items, with specified serving sizes described in terms of the natural portion or the standard weight and volume measurement of servings commonly consumed in general Japanese populations ${ }^{(27)}$. The BDHQ was developed based on a comprehensive version of a self-administered diet history questionnaire ${ }^{(28-30)}$. Estimates of mean daily intakes of energy, vitamin C, vitamin E, $\alpha$-carotene and $\beta$-carotene were calculated using an $\mathrm{ad}$ hoc computer algorithm for the BDHQ, which was based on the Standard Tables of Food Composition in Japan ${ }^{(31)}$. Information on dietary supplement use was not available to the investigators and therefore antioxidant nutrient intake from dietary supplements was not incorporated into the analysis. Mean daily intakes of vegetables and fruits were also evaluated from the information reported in the BDHQ. Dietary antioxidant, vegetable and fruit intakes were energy-adjusted (i.e. amount per $4184 \mathrm{~kJ} / 1000 \mathrm{kcal}$ for each variable).

\section{Dental examination}

Dental examinations were carried out at baseline (2003) and after 2 years of follow-up (2005). The same methods as in the baseline survey were used in the follow-up dental examination. The number of teeth present and periodontal condition were assessed. Periodontal condition was specifically assessed as measured clinical 
attachment level (CAL). CAL was recorded by calibrated examiners as previously reported ${ }^{(3)}$. Teeth were examined at six sites per tooth for all teeth present, and measurements were recorded to the nearest millimetre.

CAL refers to the amount of space between the attached periodontal tissue and the cementoenamel junction. As periodontal disease progresses, loss of periodontal attachment can occur through the inflammatory destruction of the periodontal ligament and its adjacent alveolar bone, subsequently leading to pathological periodontal pockets (Fig. 1). Therefore, CAL reflects the severity of periodontal disease and longitudinal increases in CAL values can be used as an indicator to estimate the progression of periodontal disease over time. In the present study, loss of attachment of $3 \mathrm{~mm}$ or greater over the 2-year study period (e.g. CAL $1 \mathrm{~mm}$ at baseline $+3 \mathrm{~mm}$ increase $=4 \mathrm{~mm}$ at follow-up) at an interproximal site for each tooth was considered periodontal disease progression ${ }^{(32,33)}$. Then the number of teeth with periodontal disease progression (i.e. demonstrating a longitudinal loss of proximal attachment of $\geq 3 \mathrm{~mm}$ ) was summed up for each participant.

\section{Biochemical examination of blood}

Biochemical values, including serum levels of albumin and glycated $\mathrm{Hb}$ (HbA1c), were evaluated. Hypoalbuminaemia was defined as albumin $\leq 4 \cdot 0 \mathrm{~g} / \mathrm{dl}$ and hyperglycaemia was defined as $\mathrm{HbA} 1 \mathrm{c} \geq 6 \cdot 5 \%$.

\section{Interview and anthropometric evaluation}

An interview was conducted on all participants including establishment of smoking status, with those reporting any smoking history classified as smokers. Information about socio-economic status (household income and years of school attendance) and oral health-related behaviours (brushing frequency $(<2 / \mathrm{d}$ or $\geq 2 / \mathrm{d}$ ), use of devices for inter-dental cleaning (yes or no) and the pattern of visits to a dentist) was also gathered. Lower income was defined as annual household income $<2000000$ Japanese Yen (\$US 16667; \$US $1=120$ Japanese Yen; hourly minimum wage in Niigata $=641$ Japanese Yen in 2003) and lower education was defined as school attendance $\leq 10$ years. Regular dental visits were defined as having regular periodontal examination and professional teeth cleaning at least once annually ${ }^{(34)}$.

Anthropometric evaluation included measurements of weight and height to calculate BMI (weight (kg)/ [height $(\mathrm{m})]^{2}$ ).

\section{Statistical analyses}

Differences in selected characteristics between study participants and withdrawals were compared with the use of independent $t$ tests and $\chi^{2}$ tests.

The primary outcome for the analyses was the number of teeth with periodontal disease progression, modelled as count data. Univariable and multivariable
Poisson regression analyses were performed to evaluate associations between intake of dietary antioxidants and the number of teeth with periodontal disease progression. As the main exposure in the analyses, dietary antioxidant nutrient, vegetable and fruit intakes were modelled as tertiles. Potential confounders controlled for included the number of teeth present at baseline, mean CAL at baseline, gender, lower income, lower education, BMI, hypoalbuminaemia, hyperglycaemia, smoking status, brushing frequency, use of devices for inter-dental cleaning and the pattern of visits to a dentist. Effect modification by gender and smoking was evaluated using interaction terms.

The level of significance was set at $\alpha=0 \cdot 05$. All calculations and statistical analyses were performed using the STATA ${ }^{\mathrm{TM}}$ software package version 10 (Stata Corp., College Station, TX, USA).

\section{Results}

Selected characteristics of study participants and withdrawals are listed in Table 1. No significant differences were found between the two groups. Median (25th, 75th percentile) CAL of the average study participant was $3 \cdot 1(2 \cdot 5,3 \cdot 7) \mathrm{mm}$ at baseline and $3 \cdot 1(2 \cdot 6,3 \cdot 9) \mathrm{mm}$ at follow-up, respectively. Table 2 presents participants' dietary antioxidant, vegetable and fruit intakes.

The frequencies of participants by the number of teeth with periodontal disease progression are presented in Fig. 3.

\section{Associations between the number of teeth with periodontal disease progression and dietary antioxidant intakes}

Table 3 shows crude and adjusted associations between the number of teeth with periodontal disease progression and dietary antioxidant intakes. There were no interactions of dietary antioxidants with gender and smoking status. In univariable models, significant inverse relationships of the number of teeth with periodontal disease progression with daily intakes of vitamin $\mathrm{C}$, vitamin $\mathrm{E}$, $\alpha$-carotene and $\beta$-carotene were found (Table 3 ). A high dietary intake of antioxidants was significantly associated with a smaller number of teeth with periodontal disease progression. The crude incidence rate ratios (IRR) for the mean number of teeth with periodontal disease progression in the first, second and third tertiles were, respectively: $1.00,0.73(95 \% \mathrm{CI} 0.58,0.92)$ and 0.61 (95\% CI $0 \cdot 48,0 \cdot 77)$ for vitamin C; $1 \cdot 00,0 \cdot 71$ (95\% CI $0.57,0.89)$ and $0.47(95 \%$ CI $0.36,0.61)$ for vitamin $\mathrm{E}$; $1 \cdot 00,0 \cdot 87(95 \%$ CI $0 \cdot 70,1 \cdot 10)$ and $0.72(95 \%$ CI 0.56 , $0 \cdot 92)$ for $\alpha$-carotene; and $1 \cdot 00,0 \cdot 92$ (95\% CI $0 \cdot 74,1 \cdot 15)$, and $0 \cdot 64(95 \%$ CI $0 \cdot 50,0 \cdot 82)$ for $\beta$-carotene (Table 3$)$. Vitamin $C, E$ and $\beta$-carotene remained significant after simultaneously adjusting for the number of teeth present 
Table 1 Selected characteristics of study participants and withdrawals; individuals aged 75 years in 2003, Niigata City, Japan

\begin{tabular}{|c|c|c|c|c|c|}
\hline \multirow[b]{2}{*}{ Variable } & \multicolumn{2}{|c|}{ Participants (n 264) } & \multicolumn{2}{|c|}{ Withdrawalst $(n 70)$} & \multirow[b]{2}{*}{$P \ddagger$} \\
\hline & Mean or $n$ & SD or \% & Mean or $n$ & SD or $\%$ & \\
\hline \multicolumn{6}{|l|}{ Dental conditions } \\
\hline Number of teeth at baseline & $18 \cdot 4$ & $8 \cdot 4$ & $16 \cdot 6$ & $8 \cdot 5$ & $0 \cdot 129$ \\
\hline Number of teeth at follow-up & $17 \cdot 8$ & $8 \cdot 4$ & \multirow{2}{*}{\multicolumn{2}{|c|}{$\begin{array}{l}\mathrm{N} / \mathrm{A} \\
\mathrm{N} / \mathrm{A}\end{array}$}} & $\mathrm{N} / \mathrm{A}$ \\
\hline Number of lost teeth & $0 \cdot 6$ & $1 \cdot 1$ & & & $\mathrm{~N} / \mathrm{A}$ \\
\hline Average CAL at baseline & $3 \cdot 3$ & $1 \cdot 0$ & \multirow{2}{*}{\multicolumn{2}{|c|}{$3 \cdot 4$}} & $0 \cdot 410$ \\
\hline Average CAL at follow-up & $3 \cdot 4$ & $1 \cdot 1$ & & & $\mathrm{~N} / \mathrm{A}$ \\
\hline Number of teeth with periodontal disease progression & $1 \cdot 5$ & $2 \cdot 2$ & & & $\mathrm{~N} / \mathrm{A}$ \\
\hline \multicolumn{6}{|l|}{ Demographic and socio-economic status } \\
\hline \multicolumn{6}{|l|}{ Gender } \\
\hline Men & 141 & $53 \cdot 4$ & 32 & $45 \cdot 7$ & \multirow[t]{2}{*}{$0 \cdot 252$} \\
\hline Women & 123 & $46 \cdot 6$ & 38 & $54 \cdot 3$ & \\
\hline Lower income & 30 & $11 \cdot 4$ & 13 & $18 \cdot 6$ & $0 \cdot 109$ \\
\hline Lower education & 148 & $56 \cdot 1$ & 39 & $55 \cdot 7$ & 0.959 \\
\hline \multicolumn{6}{|l|}{ Health status and health behaviours } \\
\hline BMI $\left(\mathrm{kg} / \mathrm{m}^{2}\right)$ & $23 \cdot 0$ & $3 \cdot 0$ & \multicolumn{2}{|l|}{$22 \cdot 5$} & $0 \cdot 192$ \\
\hline Hypoalbuminaemia & 103 & $39 \cdot 0$ & 23 & $32 \cdot 9$ & $0 \cdot 345$ \\
\hline Hyperglyacemia & 22 & $8 \cdot 3$ & 5 & $7 \cdot 1$ & $0 \cdot 745$ \\
\hline \multicolumn{6}{|l|}{ Smoking status } \\
\hline Smoker & 126 & $47 \cdot 7$ & 32 & $45 \cdot 7$ & \multirow[t]{2}{*}{$0 \cdot 764$} \\
\hline Non-smoker & 138 & $52 \cdot 3$ & 38 & $54 \cdot 3$ & \\
\hline \multicolumn{6}{|l|}{ Brushing frequency } \\
\hline$<2 / d$ & 82 & $31 \cdot 1$ & 17 & $24 \cdot 3$ & \multirow[t]{2}{*}{$0 \cdot 270$} \\
\hline$\geq 2 / d$ & 182 & $68 \cdot 9$ & 53 & $75 \cdot 7$ & \\
\hline \multicolumn{6}{|l|}{ Devices for inter-dental cleaning } \\
\hline Not used & 130 & $49 \cdot 2$ & 39 & $55 \cdot 7$ & \multirow[t]{2}{*}{$0 \cdot 336$} \\
\hline Used & 134 & $50 \cdot 8$ & 31 & $44 \cdot 3$ & \\
\hline \multicolumn{6}{|l|}{ Regular dental visits } \\
\hline No & 123 & $46 \cdot 6$ & 37 & $52 \cdot 9$ & \multirow[t]{2}{*}{$0 \cdot 351$} \\
\hline Yes & 141 & $53 \cdot 4$ & 33 & $47 \cdot 1$ & \\
\hline
\end{tabular}

CAL, clinical attachment level; N/A, not available.

Lower income = annual household income $<2000000$ Japanese Yen; lower education = school attendance $\leq 10$ years; hypoalbuminaemia $=$ albumin $\leq 4 \cdot 0 \mathrm{~g} / \mathrm{dl}$; hyperglycaemia $=\mathrm{HbA} 1 \mathrm{c} \geq 6.5 \%$; regular dental visits $=$ having regular periodontal examination and professional teeth cleaning at least once annually. +Withdrawal = person who participated in baseline examination but did not return for follow-up ( $n$ 69) and person who became edentulous during the study ( $n 1$ ). $\ddagger P$ value for the comparison of selected characteristics between participants and withdrawals.

Table 2 Intakes of dietary antioxidants, vegetables and fruits at baseline; dentate individuals ( $n$ 264) aged 75 years in 2003, Niigata City, Japan

\begin{tabular}{|c|c|c|c|c|c|c|c|}
\hline & Mean & SD & Minimum & 33rd percentile & Median & 66th percentile & Maximum \\
\hline \multicolumn{8}{|l|}{ Antioxidantstł } \\
\hline Vitamin $C(\mathrm{mg} / \mathrm{d})$ & $91 \cdot 4$ & $27 \cdot 3$ & $22 \cdot 3$ & $80 \cdot 5$ & $91 \cdot 8$ & $100 \cdot 4$ & $195 \cdot 6$ \\
\hline Vitamin E (mg/d) & $5 \cdot 2$ & $1 \cdot 0$ & $2 \cdot 0$ & $4 \cdot 4$ & $5 \cdot 3$ & $5 \cdot 6$ & $7 \cdot 9$ \\
\hline$\alpha$-Carotene $(\mu \mathrm{g} / \mathrm{d})$ & $284 \cdot 8$ & $184 \cdot 8$ & 0.5 & $174 \cdot 4$ & $274 \cdot 7$ & $339 \cdot 3$ & $1080 \cdot 4$ \\
\hline$\beta$-Carotene $(\mu \mathrm{g} / \mathrm{d})$ & $2639 \cdot 1$ & $1169 \cdot 6$ & $205 \cdot 4$ & $2036 \cdot 2$ & $2595 \cdot 2$ & $3006 \cdot 9$ & $7070 \cdot 8$ \\
\hline \multicolumn{8}{|l|}{ Vegetables and fruitstł } \\
\hline Vegetables $(\mathrm{g} / \mathrm{d})$ & $181 \cdot 2$ & $65 \cdot 4$ & $40 \cdot 8$ & $148 \cdot 2$ & $178 \cdot 4$ & $205 \cdot 0$ & $398 \cdot 2$ \\
\hline Fruits $(g / d)$ & $69 \cdot 1$ & $36 \cdot 5$ & 0 & $51 \cdot 4$ & $67 \cdot 9$ & $83 \cdot 6$ & $183 \cdot 2$ \\
\hline
\end{tabular}

tEnergy-adjusted (i.e. amount per $4184 \mathrm{~kJ} / 1000 \mathrm{kcal}$ for each variable).

‡Participants' mean energy intake $=9314$ (SD 2657) kJ/2226.1 (sD 635.0) kcal.

at baseline, mean CAL at baseline, gender, lower income, lower education, BMI, hypoalbuminaemia, hyperglycaemia, smoking status, brushing frequency, use of devices for inter-dental cleaning and the pattern of visits to a dentist. The multivariate-adjusted IRR in the first, second and third tertiles were, respectively: $1 \cdot 00,0 \cdot 76$ (95\% CI $0.60,0.97)$ and $0.72(95 \%$ CI $0.56,0.93)$ for vitamin C; $1.00,0.79(95 \%$ CI $0.62,0.99)$ and 0.55 (95\% CI 0.42 , $0 \cdot 72$ ) for vitamin $\mathrm{E}$; and $1 \cdot 00,1 \cdot 02(95 \% \mathrm{CI} 0 \cdot 81,1 \cdot 29)$ and $0.73(95 \%$ CI $0.56,0.95)$ for $\beta$-carotene (Table 3$)$. There was no statistical association between the number of teeth with periodontal disease progression and dietary $\alpha$-carotene in the multivariable model (Table 3).

\section{Associations between the number of teeth with periodontal disease progression and vegetable and fruit intakes}

Table 3 shows crude and adjusted associations between the number of teeth with periodontal disease progression and vegetable and fruit intakes. In multivariable modelling, significant inverse associations were found between intakes of vegetables and fruits and the number of teeth 


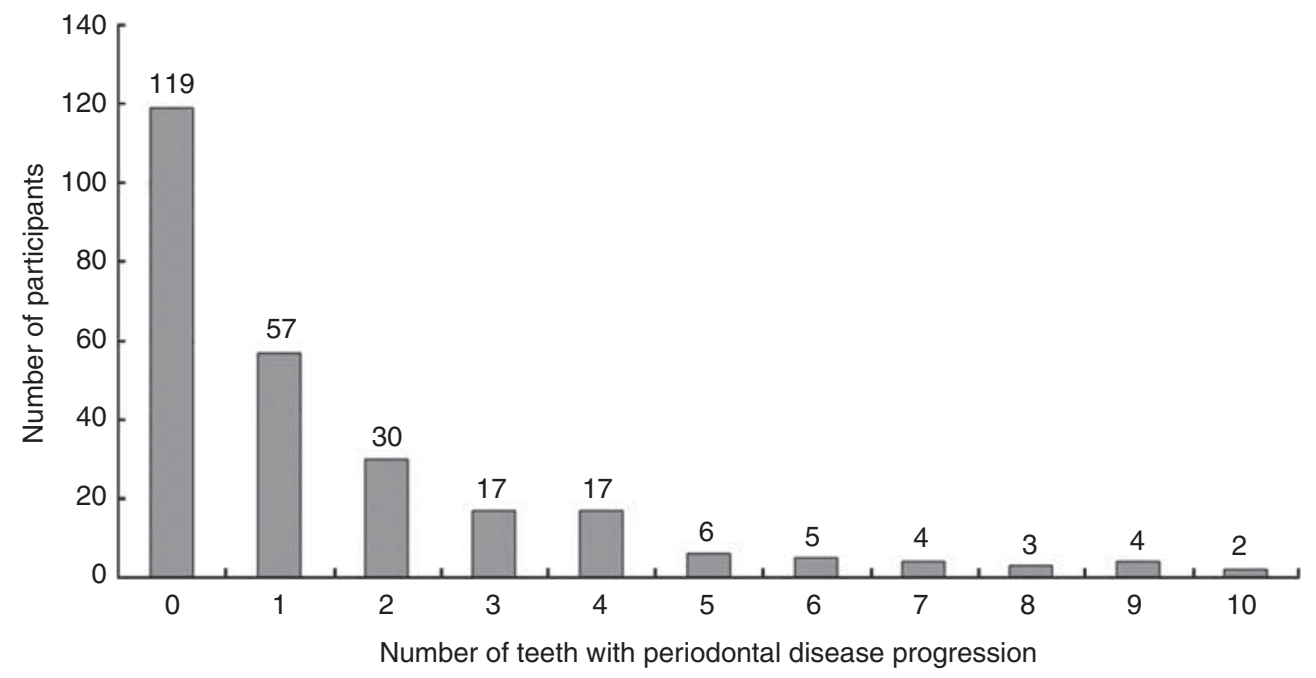

Fig. 3 Frequency of participants by the number of teeth with periodontal disease progression; dentate individuals ( $n$ 264) aged 75 years in 2003, Niigata City, Japan

Table 3 Associations of intakes of dietary antioxidants, vegetables and fruits with the number of teeth with periodontal disease progression; dentate individuals ( $n$ 264) aged 75 years in 2003, Niigata City, Japan

\begin{tabular}{|c|c|c|c|c|c|c|}
\hline & \multicolumn{2}{|c|}{$\begin{array}{l}\text { Outcome: Number of teeth with } \\
\text { periodontal disease progression }\end{array}$} & \multirow[b]{2}{*}{$\mathrm{IRR}_{\text {Crude }}$} & \multirow[b]{2}{*}{$95 \% \mathrm{Cl}$} & \multirow[b]{2}{*}{$\mathrm{IRR}_{\mathrm{Adj}}$} & \multirow[b]{2}{*}{$95 \% \mathrm{Cl}$} \\
\hline & Mean & SD & & & & \\
\hline \multicolumn{7}{|l|}{ Exposure: Antioxidantst } \\
\hline \multicolumn{7}{|l|}{ Vitamin C (mg/d) } \\
\hline Lowest (reference) & $2 \cdot 0$ & $2 \cdot 5$ & \multicolumn{2}{|c|}{$1 \cdot 00$} & \multicolumn{2}{|c|}{$1 \cdot 00$} \\
\hline Middle & $1 \cdot 4$ & $2 \cdot 2$ & $0.73^{*}$ & $0.58,0.92$ & $0 \cdot 76$ * & $0.60,0.97$ \\
\hline Highest & $1 \cdot 2$ & $1 \cdot 7$ & $0 \cdot 61^{*}$ & $0.48,0.77$ & $0 \cdot 72^{*}$ & $0.56,0.93$ \\
\hline \multicolumn{7}{|l|}{ Vitamin E (mg/d) } \\
\hline Lowest (reference) & $2 \cdot 1$ & $2 \cdot 5$ & \multicolumn{2}{|c|}{$1 \cdot 00$} & \multicolumn{2}{|c|}{$1 \cdot 00$} \\
\hline Middle & $1 \cdot 5$ & $2 \cdot 2$ & $0 \cdot 71^{*}$ & $0.57,0.89$ & $0 \cdot 79^{\star}$ & $0.62,0.99$ \\
\hline Highest & $1 \cdot 0$ & $1 \cdot 6$ & $0.47^{*}$ & $0 \cdot 36,0 \cdot 61$ & $0 \cdot 55^{\star}$ & $0.42,0.72$ \\
\hline \multicolumn{7}{|l|}{$\alpha$-Carotene $(\mu \mathrm{g} / \mathrm{d})$} \\
\hline Lowest (reference) & $1 \cdot 8$ & $2 \cdot 5$ & \multicolumn{2}{|c|}{1.00} & \multicolumn{2}{|c|}{$1 \cdot 00$} \\
\hline Middle & 1.5 & $2 \cdot 1$ & $0 \cdot 87$ & $0 \cdot 70,1 \cdot 10$ & $1 \cdot 06$ & $0 \cdot 82,1 \cdot 36$ \\
\hline Highest & $1 \cdot 3$ & $1 \cdot 8$ & $0 \cdot 72^{*}$ & $0.56,0.92$ & 0.89 & $0 \cdot 68,1 \cdot 15$ \\
\hline \multicolumn{7}{|l|}{$\beta$-Carotene $(\mu \mathrm{g} / \mathrm{d})$} \\
\hline Lowest (reference) & $1 \cdot 8$ & $2 \cdot 5$ & \multicolumn{2}{|c|}{1.00} & \multicolumn{2}{|c|}{$1 \cdot 00$} \\
\hline Middle & $1 \cdot 6$ & $2 \cdot 2$ & 0.92 & $0 \cdot 74,1 \cdot 15$ & $1 \cdot 02$ & $0.81,1 \cdot 29$ \\
\hline Highest & $1 \cdot 1$ & $1 \cdot 6$ & $0.64^{*}$ & $0.50,0.82$ & $0 \cdot 73^{*}$ & $0.56,0.95$ \\
\hline \multicolumn{7}{|c|}{ Exposure: Vegetables and fruitst } \\
\hline \multicolumn{7}{|c|}{ Vegetables $(\mathrm{g} / \mathrm{d})$} \\
\hline Lowest (reference) & $1 \cdot 9$ & $2 \cdot 7$ & \multicolumn{2}{|c|}{1.00} & \multicolumn{2}{|c|}{1.00} \\
\hline Middle & $1 \cdot 6$ & $2 \cdot 1$ & $0 \cdot 84$ & $0 \cdot 67,1 \cdot 05$ & 0.94 & $0 \cdot 74,1 \cdot 19$ \\
\hline Highest & $1 \cdot 1$ & $1 \cdot 4$ & $0.58^{\star}$ & $0 \cdot 45,0 \cdot 74$ & $0 \cdot 68^{*}$ & $0.52,0.88$ \\
\hline \multicolumn{7}{|l|}{ Fruits $(g / d)$} \\
\hline Lowest (reference) & $1 \cdot 9$ & $2 \cdot 4$ & \multicolumn{2}{|c|}{1.00} & \multicolumn{2}{|c|}{$1 \cdot 00$} \\
\hline Middle & $1 \cdot 5$ & $2 \cdot 3$ & $0.79^{*}$ & $0.63,0.99$ & 0.88 & $0.69,1 \cdot 11$ \\
\hline Highest & $1 \cdot 2$ & $1 \cdot 6$ & $0.62^{\star}$ & $0.49,0.80$ & $0 \cdot 74^{\star}$ & $0.57,0.95$ \\
\hline
\end{tabular}

with periodontal disease progression. The multivariate adjusted IRR in the first, second and third tertiles were, respectively: $1 \cdot 00,0.94(95 \%$ CI $0.74,1 \cdot 19)$ and 0.68
(95\% CI $0 \cdot 52,0 \cdot 88)$ for vegetables; and $1 \cdot 00,0 \cdot 88$ (95\% CI $0.69,1 \cdot 11)$ and $0.74(95 \%$ CI $0.57,0 \cdot 95)$ for fruits (Table 3). 


\section{Discussion}

The present study is the first longitudinal one to show a relationship between dietary antioxidants and periodontal disease. The findings show that higher intakes of the antioxidants vitamin $\mathrm{C}$, vitamin $\mathrm{E}$ and $\beta$-carotene were associated with lower number of teeth with periodontal disease progression in older Japanese people. These effects were independent of several potential confounders. Although not all antioxidant intake tertile categories had statistically significantly different individual-level periodontal disease progression compared with the lowest tertile reference group, there was a tendency for a smaller number of teeth with periodontal disease progression with higher antioxidant intake. For vitamins $\mathrm{C}$ and $\mathrm{E}$ there were also significant decreased risks in the middle compared with the lowest tertile. However, differences between middle and lowest tertiles did not reach significance for $\beta$-carotene. There are several explanations. First, sample size limitations may lead to the lack of statistical significance of the three-category specification of $\beta$-carotene intake. Second, there may be a threshold for the amount of $\beta$-carotene intake that contributes to protection against periodontal disease.

A number of studies have demonstrated that oxidative stress can be mitigated by antioxidants, including vitamin C, vitamin $\mathrm{E}$ and carotenoids ${ }^{(35-40)}$, which could help explain the observed association between antioxidants and periodontal disease. Dietary antioxidants might play a beneficial role by reducing the levels of oxidative stress in periodontal tissues. It has been demonstrated that dietary intakes of vitamin $\mathrm{C}$ (mean $54 \cdot 2(\mathrm{sD} 35 \cdot 4) \mathrm{mg} / \mathrm{d}$ ), vitamin E (mean $5 \cdot 8(\mathrm{sD} 2 \cdot 0) \mathrm{mg} / \mathrm{d}$ ) and $\beta$-carotene (mean 1.7 (sD 1.4$) \mathrm{mg} / \mathrm{d}$ ) were negatively associated with oxidative stress biomarkers among 704 participants aged 70 years in a 7 -year Swedish cohort study ${ }^{(41)}$. The potential relationship between dietary antioxidants and periodontal disease is also supported by a randomized trial that examined the efficacy of an antioxidant supplement on periodontal disease among smokers. Grossi and colleagues demonstrated significant improvements in CAL among those taking single-dose vitamin C/vitamin $\mathrm{E} /$ grape seed extract ( $1100 \mathrm{mg}$ vitamin C, $135 \mathrm{mg}$ vitamin $\mathrm{E}$, $42 \mathrm{mg}$ grape seed) and double-dose supplements compared with the placebo group ${ }^{(42)}$. However, these are pharmaceutical doses that cannot be achieved through consumption of a normal diet. The present study results suggest that antioxidant nutrient levels which can be obtained through diet have a positive impact on the periodontal tissues.

The mean levels of intake of antioxidants (not including supplements) in the present study were $202 \cdot 4$ (SD 79.9) $\mathrm{mg} / \mathrm{d}$ for vitamin C, $11.5(\mathrm{sD} 4 \cdot 2) \mathrm{mg} / \mathrm{d}$ for vitamin E, 625.4 (SD 416.9) $\mu \mathrm{g} / \mathrm{d}$ for $\alpha$-carotene and 5841.7 (SD 2951.1) $\mu \mathrm{g} / \mathrm{d}$ for $\beta$-carotene. These levels are higher than those reported in other countries. In the
British National Diet and Nutrition Survey (NDNS) of people aged 65 years or over $(n 1054)^{(43)}$, the mean dietary intakes were $71 \cdot 1(\mathrm{sD} 70 \cdot 5) \mathrm{mg} / \mathrm{d}$ among men and 65.4 (SD $57 \cdot 1$ ) $\mathrm{mg} / \mathrm{d}$ among women for vitamin $\mathrm{C}$, and 9.5 (sD $8 \cdot 2) \mathrm{mg} / \mathrm{d}$ among men and $10 \cdot 7$ (sD 39.4) $\mathrm{mg} / \mathrm{d}$ among women for vitamin E. In the National Health and Nutrition Examination Survey (NHANES) 1999-2000, for the US population aged 60 years and over $(n 1537)^{(44)}$, the mean dietary intakes were $104(\mathrm{sD} 4.6) \mathrm{mg} / \mathrm{d}$ for vitamin C and $8.3(\mathrm{sD} 0.3) \mathrm{mg} / \mathrm{d}$ for vitamin $\mathrm{E}$. These differences may in part be due to between-survey differences in dietary methodology as FFQ have a tendency to overestimate absolute levels of intake. This is supported by the observation that the levels of antioxidant intakes among participants in the present study are also higher than those reported for Japanese people aged 75 years and over in the National Nutrition Survey in Japan (J-NNS) ${ }^{(45)}$. In the J-NNS of people aged 75 years or over ( $n$ 1168), the mean dietary intakes were 138 (SD 127) $\mathrm{mg} / \mathrm{d}$ for vitamin $\mathrm{C}$ and 9.9 (SD 28.9) $\mathrm{mg} / \mathrm{d}$ for vitamin $\mathrm{E}$. Unfortunately, neither the UK NDNS nor the US NHANES survey reports intake of vitamins adjusted for energy intake, which makes comparison with the present data difficult. However, the data from the J-NNS suggest that Japanese older people consume a higher level of nutrients than Western older populations.

In the present study, a high intake of fruits and vegetables was protective against periodontal disease. This concurs with previous data from Japan ( $n$ 261, 70 years) which showed the intake of vegetables was negatively correlated with periodontal disease ${ }^{(46)}$. Moreover, a significant inverse dose-response relationship between intake of vegetables other than yellow and green vegetables (such as cabbages, radishes and onions) and the prevalence of tooth loss was demonstrated among 1002 Japanese women ${ }^{(47)}$. From the these findings, it may therefore be concluded that dietary modification to increase the consumption of fruits and vegetables and other foods containing vitamin $\mathrm{C}$, vitamin $\mathrm{E}$ and carotenoids may be beneficial to oral health and have a therapeutic and preventive role in periodontal disease.

In this cohort, a homogeneous group restricted to the age of 75 years at baseline was selected to exclude the influence of race and age variation in the results. Among 334 study entrants (173 men and 161 women) seventy did not complete the study because they were unable to participate in the follow-up survey or became edentulous (Fig. 2). Individuals who withdrew were excluded from the following statistical analyses. There was no significant difference in dental conditions, demographic, socio-economic and health status and health behaviours between withdrawals and study participants; however, there is the potential risk that our final sample analysed ( $n$ 264) may not be representative of the originally sampled cohort ( $n 600)$. At baseline, four of 370 individuals did not submit complete data. We could 
not access the information on oral and systemic health and nutrient intakes of these individuals, and therefore we could not assess whether there were differences in these characteristics between the 334 study entrants and the four individuals who did not submit complete data. Additionally, the edentulous group ( $n$ 32) who were excluded from further analysis had a higher prevalence of hyperglycaemia and poorer oral health behaviour (i.e. did not visit a dentist regularly; data not shown). During 1998-2003, 230 of the 600 original participants were withdrawn from the study. Compared with the 370 individuals who undertook baseline assessments for the current study, the 230 withdrawals had poorer oral health behaviour in 1998 (data not shown). In this context, the current sample may be healthier than the general population; however, the healthy cohort effect would probably bias the results toward the null hypothesis and not lead to overestimation of the observed longitudinal associations.

There are several other limitations to the present study. First, our study period was only 2 years. In the present study, it is not possible to assess the effects of dietary antioxidants on periodontal conditions that could occur further out than 2 years. Over- or underestimation of the observed association between dietary antioxidants and periodontal disease caused by this short study period remains a risk. Second, the participants were restricted to the age of 75 years. At this age, they might have already changed their usual dietary intake due to tooth loss or use of dentures ${ }^{(48)}$. The mean number of teeth in the study participants was $18.4(\mathrm{SD} 8 \cdot 4)$ at baseline and $17 \cdot 8$ (SD 8.4) at follow-up. Reverse causality (i.e. dentition status affects nutrient intake) may weaken any true association as the limited number of teeth among the study participants could lead to a reduced consumption of vegetables and fruits $^{(49)}$ and therefore low intake of antioxidant vitamins. Future work with larger, more diversified, full dentate samples and over longer periods of time would be necessary to substantiate our findings. Third, information on nutritional supplement use was not available; therefore, it was not possible to assess with complete accuracy the amount of dietary antioxidants, leading to potential misclassification. In the National Health and Nutrition Survey Japan 2003 of people aged 70 years or over $\left(n\right.$ 1800) ${ }^{(50)}$, the mean intake of vitamins from supplemental sources was 21 (SD 215) $\mathrm{mg} / \mathrm{d}$ for vitamin $\mathrm{C}$ and 4.6 (SD 37.6$) \mathrm{mg} / \mathrm{d}$ for vitamin E. Finally, because other information regarding participants' oral health status (e.g. dental plaque scores, subgingival biofilm, history of periodontal treatment), medication use or physician's diagnosis of related diseases (e.g. diabetes ${ }^{(4)}$ ) was not collected, a number of other potentially important risk factors could not be assessed in the analyses. Although the most important confounders were assessed, overestimation of the observed association between antioxidant intake and periodontal disease caused by residual confounding remains a risk.

\section{Conclusions}

Within the limitations of the present study, the reported findings suggest an independent relationship of intake of dietary antioxidants, and intake of fruits and vegetables, with periodontal disease progression among older Japanese. Further studies are necessary to substantiate these findings and evaluate the effectiveness of dietary modification to increase antioxidant intake in controlling periodontal disease.

\section{Acknowledgements}

This work was supported by grants-in-aid from the Ministry of Health and Welfare of Japan (H10-Iryo-001, H13-Iryo-001 and H16-Iryo-020) and a grant for promotion of Niigata University Research Projects (23C068). The authors have no conflict of interests to report. The authors' contributions were as follows: M.I., corresponding author; P.M., conception and design of study, interpretation of data; M.C.M., conception and design of study, analysis and interpretation of data; G.W.T., conception and design of study; A.Y., conception and design of study, collection of data; K.M., collection of data; R.W., collection of data; H.M., conception and design of study, collection of data ethics.

\section{References}

1. Petersen PE \& Ogawa H (2005) Strengthening the prevention of periodontal disease: the WHO approach. $J$ Periodontol 76, 2187-2193.

2. Locker D, Ford J \& Leake JL (1996) Incidence of and risk factors for tooth loss in a population of older Canadians. J Dent Res 75, 783-789.

3. Iwasaki M, Yoshihara A, Hirotomi $\mathrm{T}$ et al. (2008) Longitudinal study on the relationship between serum albumin and periodontal disease. J Clin Periodontol 35, 291-296.

4. Taylor GW (2001) Bidirectional interrelationships between diabetes and periodontal diseases: an epidemiologic perspective. Ann Periodontol 6, 99-112.

5. Axelsson P, Paulander J \& Lindhe J (1998) Relationship between smoking and dental status in 35-, 50-, 65-, and 75-year-old individuals. J Clin Periodontol 25, 297-305.

6. Chapple IL \& Matthews JB (2007) The role of reactive oxygen and antioxidant species in periodontal tissue destruction. Periodontol 2000 43, 160-232.

7. Sies H (1991) Oxidative stress: introduction. In Oxidative Stress: Oxidants and Antioxidants, pp. 15-21 [H Sies, editor]. London: Academic Press.

8. Chapple IL (1996) Role of free radicals and antioxidants in the pathogenesis of the inflammatory periodontal diseases. Clin Mol Pathol 49, M247-M255.

9. Chapple IL (1997) Reactive oxygen species and antioxidants in inflammatory diseases. J Clin Periodontol 24, 287-296.

10. Waddington RJ, Moseley R \& Embery G (2000) Reactive oxygen species: a potential role in the pathogenesis of periodontal diseases. Oral Dis 6, 138-151.

11. Lee NK, Choi YG, Baik JY et al. (2005) A crucial role for reactive oxygen species in RANKL-induced osteoclast differentiation. Blood 106, 852-859. 
12. Maritim AC, Sanders RA \& Watkins JB 3rd (2003) Diabetes, oxidative stress, and antioxidants: a review. J Biochem Mol Toxicol 17, 24-38.

13. Ozkan Y, Yardym-Akaydyn S, Sepici A et al. (2007) Oxidative status in rheumatoid arthritis. Clin Rheumatol 26, 64-68.

14. Wolfram R, Oguogho A, Palumbo B et al. (2005) Enhanced oxidative stress in coronary heart disease and chronic heart failure as indicated by an increased 8-epi-PGF( 2 alpha). Eur J Heart Fail 7, 167-172.

15. Hertog MG, Feskens EJ, Hollman PC et al. (1993) Dietary antioxidant flavonoids and risk of coronary heart disease: the Zutphen Elderly Study. Lancet 342, 1007-1011.

16. Institute of Medicine (1998) Dietary Reference Intakes. Proposed Definition and Plan for Review of Dietary Antioxidant and Related Compounds. Washington, DC: National Academy Press.

17. Knekt P, Ritz J, Pereira MA et al. (2004) Antioxidant vitamins and coronary heart disease risk: a pooled analysis of 9 cohorts. Am J Clin Nutr 80, 1508-1520.

18. Rock CL, Jacob RA \& Bowen PE (1996) Update on the biological characteristics of the antioxidant micronutrients: vitamin C, vitamin E, and the carotenoids. J Am Diet Assoc 96, 693-702.

19. Thurnham DI (1994) Carotenoids: functions and fallacies. Proc Nutr Soc 53, 77-87.

20. Nishida M, Grossi SG, Dunford RG et al. (2000) Dietary vitamin $\mathrm{C}$ and the risk for periodontal disease. J Periodontol 71, 1215-1223.

21. Chapple ILC, Milward MR \& Dietrich T (2007) The prevalence of inflammatory periodontitis is negatively associated with serum antioxidant concentrations. J Nutr 137, 657-664.

22. Brock GR, Butterworth CJ, Matthews JB et al. (2004) Local and systemic total antioxidant capacity in periodontitis and health. J Clin Periodontol 31, 515-521.

23. Sculley DV \& Langley-Evans SC (2003) Periodontal disease is associated with lower antioxidant capacity in whole saliva and evidence of increased protein oxidation. $\mathrm{Clin} \mathrm{Sci}$ (Lond) 105, 167-172.

24. Chapple IL, Brock GR, Milward MR et al. (2007) Compromised GCF total antioxidant capacity in periodontitis: cause or effect? J Clin Periodontol 34, 103-110.

25. Kim JS, Park JY, Chung WY et al. (2004) Polymorphisms in genes coding for enzymes metabolizing smoking-derived substances and the risk of periodontitis. J Clin Periodontol 31, 959-964.

26. Sasaki S (2004) Development and evaluation of dietary assessment methods using biomarkers and diet history questionnaires for individuals. In Research for Evaluation Methods of Nutrition and Dietary Lifestyle Programs Held on Healthy Japan 21. Summary Report, pp. 10-44 [H Tanaka, editor]. Tokyo: Ministry of Health, Welfare, and Labour (in Japanese)

27. Murakami K, Mizoue T, Sasaki S et al. (2008) Dietary intake of folate, other B vitamins, and omega- 3 polyunsaturated fatty acids in relation to depressive symptoms in Japanese adults. Nutrition 24, 140-147.

28. Sasaki S, Ushio F, Amano K et al. (2000) Serum biomarkerbased validation of a self-administered diet history questionnaire for Japanese subjects. J Nutr Sci Vitaminol (Tokyo) 46, 285-296.

29. Sasaki S, Yanagibori R \& Amano K (1998) Self-administered diet history questionnaire developed for health education: a relative validation of the test-version by comparison with 3-day diet record in women. J Epidemiol 8, 203-215.

30. Sasaki S, Yanagibori R \& Amano K (1998) Validity of a selfadministered diet history questionnaire for assessment of sodium and potassium: comparison with single 24-hour urinary excretion. Jpn Circ J 62, 431-435.

31. Science and Technology Agency (2005) Standard Tables of Food Composition in Japan, 5th revised ed. Tokyo: National Printing Bureau (in Japanese).

32. Brown LF, Beck JD \& Rozier RG (1994) Incidence of attachment loss in community-dwelling older adults. J Periodontol 65, 316-323.

33. Tonetti MS \& Claffey N (2005) Advances in the progression of periodontitis and proposal of definitions of a periodontitis case and disease progression for use in risk factor research. Group C consensus report of the 5th European Workshop in Periodontology. J Clin Periodontol 32, Suppl. 6, 210-213.

34. Nordstrom G, Bergman B, Borg K et al. (1998) A 9-year longitudinal study of reported oral problems and dental and periodontal status in 70- and 79-year-old city cohorts in northern Sweden. Acta Odontol Scand 56, 76-84.

35. Burton GW \& Ingold KU (1984) $\beta$-Carotene: an unusual type of lipid antioxidant. Science 224, 569-573.

36. Fisher MA, Taylor GW, West BT et al. (2011) Bidirectional relationship between chronic kidney and periodontal disease: a study using structural equation modeling. Kidney Int 79, 347-355.

37. Meydani M (1995) Vitamin E. Lancet 345, 170-175.

38. Sen CK (1995) Oxidants and antioxidants in exercise. J Appl Physiol 79, 675-686.

39. Tannenbaum SR, Wishnok JS \& Leaf CD (1991) Inhibition of nitrosamine formation by ascorbic acid. Am J Clin Nutr 53, 1 Suppl., S247-S250.

40. Weber P, Bendich A \& Schalch W (1996) Vitamin C and human health - a review of recent data relevant to human requirements. Int J Vitam Nutr Res 66, 19-30.

41. Helmersson J, Arnlov J, Larsson A et al. (2009) Low dietary intake of $\beta$-carotene, $\alpha$-tocopherol and ascorbic acid is associated with increased inflammatory and oxidative stress status in a Swedish cohort. Br J Nutr 101, 1775-1782.

42. Grossi SG, Nowadly CA, Takemura A et al. (2004) Development of an antioxidant supplement for smokers with periodontal disease. J Dent Res 83, 0192.

43. Bates CJ, Hamer M \& Mishra GD (2011) Redox-modulatory vitamins and minerals that prospectively predict mortality in older British people: the National Diet and Nutrition Survey of people aged 65 years and over. Br J Nutr $\mathbf{1 0 5}$, 123-132.

44. Ervin RB, Wright JD, Wang CY et al. (2004) Dietary intake of selected vitamins for the United States population: 1999-2000. Adv Data issue 339, 1-4.

45. Katanoda K \& Matsumura Y (2002) National Nutrition Survey in Japan - its methodological transition and current findings. J Nutr Sci Vitaminol (Tokyo) 48, 423-432.

46. Yoshihara A, Watanabe R, Hanada $\mathrm{N}$ et al. (2009) A longitudinal study of the relationship between diet intake and dental caries and periodontal disease in elderly Japanese subjects. Gerodontology 26, 130-136.

47. Tanaka K, Miyake Y, Sasaki S et al. (2007) Relationship between intake of vegetables, fruit, and grains and the prevalence of tooth loss in Japanese women. J Nutr Sci Vitaminol (Tokyo) 53, 522-528.

48. Krall E, Hayes C \& Garcia R (1998) How dentition status and masticatory function affect nutrient intake. J Am Dent Assoc 129, 1261-1269.

49. Yoshihara A, Watanabe R, Nishimuta $M$ et al. (2005) The relationship between dietary intake and the number of teeth in elderly Japanese subjects. Gerodontology 22, 211-218.

50. Ministry of Health, Labour and Welfare Japan (2003) National Health and Nutrition Survey. http://www.mhlw.go.jp/bunya/ kenkou/eiyou-chosa2-01/pdf/03a.pdf (accessed February 2012). 